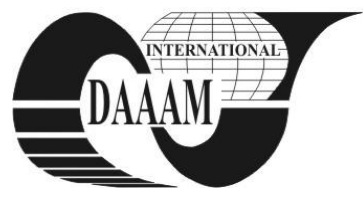

Annals of DAAAM for 2011 \& Proceedings of the 22nd International DAAAM Symposium, Volume 22, No. 1, ISSN 1726-9679 ISBN 978-3-901509-83-4, Editor B. Katalinic, Published by DAAAM International, Vienna, Austria, EU, 2011 Make Harmony between Technology and Nature, and Your Mind will Fly Free as a Bird

\title{
MONITORING DELIVERY TIME WITH CONTROL CHARTS
}

\author{
DUMICIC, K[senija] \& ZMUK, B[erislav]
}

\begin{abstract}
The aim of the research presented in this paper is to establish the role of control charts for variables as a tool in monitoring the supply delivery time. Types of wastes in Just-inTime production strategy with focus on transport wastes through supply delivery analysis are discussed. The study shows that the exponentially weighted moving average control chart is worthless in monitoring delivery time when the smoothing weight is set at the very small level. The $\bar{x}$ and the s control charts better indicate the deliveries in which a serious problem exists. The use of all three charts together is recommended.
\end{abstract}

Key words: just-in-time production strategy, delivery time, control charts for variables

\section{INTRODUCTION}

Just-in-Time (JIT) is a management philosophy which has been applied in practice since the early 1970s, first in Toyota and later in many Japanese manufacturing organizations. It is wrong thinking that JIT can only be applied in: Japan; the motor industry; or with a highly motivated workforce, because it has been successfully applied in a whole range of industries all over Europe (Booth, 1988).

JIT focuses on minimizing the size of waste that is included in the production process. There are overall seven types of wastes: waste from overproduction, waste of waiting time, transportation waste, processing waste, inventory waste, waste of motion of employees and waste from product defects (Bersbach, 2009).

The article keeps focus on detecting transport waste which is caused by inappropriate planning of delivery time of supplies. The research hypothesis is that this waste can be detected using statistical control charts for variables as a technical solution. Other authors suggest that for this purpose the usage of the exponentially weighted moving average (EWMA) chart would be appropriate (Khoo \& Quah, 2002; Takahashi, 2003). EWMA chart is somewhat complicated to interpret in analysis, average $(\bar{x})$ and standard deviation (s) charts are used, too. Use of these charts in solving the problem is exemplified by a simplified case study which should show the advantages of the control charts use in detecting transport wastes which can consequently be avoided.

\section{DATA, METHODS AND ANALYSIS}

The control charts and principles of their use were invented by Walter Shewhart in the 1920s (Shewhart, 1925). Almost ninety years after the control charts were invented they are still in use and their importance is still increasing. The main objective of control charts, as a tool of quality control, is to explain variation of important quality characteristics and to help reducing the variation eventually resulting in the process improvements.

A control chart shows the amount and nature of variation by time, enables pattern interpretation and detection of special caused changes in the process under study (Wadsworth et. al., 2002). Special-caused variations are foreseeable and they can be avoided. Using control charts the total variation can be decreased resulting in decreased cost of quality, too.

There are generally two types of data that are used in a quality characteristics study, and according to these, two types of control charts: control charts for attributes data and control charts for variables data could be distinguished. The charts that are used in this article are designed for variables data.

The average $(\bar{x})$ control chart has a good sensitivity in detecting changes in the mean of the underlying process (Wadsworth et. al., 2002). Usually the $\bar{x}$ chart is used in conjunction with one of the charts for dispersion. In this case a standard deviation (s) chart is used. Usually the mean $(\mu)$ and the standard deviation $(\sigma)$ of the process are not known, so, the control limits for the $\bar{x}$ chart are calculated as follows:

$$
\mathrm{CL}_{\overline{\mathrm{x}}}=\overline{\overline{\mathrm{x}}} \pm \mathrm{A}_{3} \overline{\mathrm{s}}
$$

where the weighted grand average $(\overline{\bar{x}})$ for the samples is computed for use as the center line of the chart, the factor $\mathrm{A}_{3}$ is tabulated, and $\bar{s}$ is the center line of the s chart. If the $\mu$ and $\sigma$ were not known, and unequal sample sizes are used in the study, the centre line and the control limits should be calculated as follows:

$$
\begin{gathered}
\bar{s}=\sqrt{\sum_{i=1}^{k}\left(n_{i}-1\right) s_{i}^{2} /\left(\sum n_{i}-k\right)} \\
\mathrm{UCL}_{\mathrm{s}}=\mathrm{B}_{4} \overline{\mathrm{s}} \\
\mathrm{LCL}_{\mathrm{s}}=\mathrm{B}_{3} \overline{\mathrm{s}},
\end{gathered}
$$

where $n_{i}$ is size of $i$-th sample, $k$ is the number of samples, and factors $\mathrm{B}_{3}$ and $\mathrm{B}_{4}$ are tabulated in Shewhart's tables.

In the analysis the exponentially weighted moving average (EWMA) control chart is used. This type of chart is more appropriate than the standard $\bar{x}$ chart for detecting small shifts in the process mean, but its construction is somewhat complicated. The control limits are calculated as follows:

$$
\mathrm{CL}_{\mathrm{EWMA}}=\overline{\bar{x}} \pm k(\hat{\sigma} / \sqrt{n}) \sqrt{[\lambda /(2-\lambda)]\left[1-(1-\lambda)^{2 t}\right]},
$$

where $\mathrm{k}$ defines the width between the control limits (usually $\mathrm{k}=3), \hat{\sigma} / \sqrt{n}$ represents the standard deviation of given samples, $\sqrt{[\lambda /(2-\lambda)]\left[1-(1-\lambda)^{2 t}\right]}$ is the factor of correction, where $\lambda$ is the weight parameter such that $0<\lambda<1$. If $\lambda$ approaches 1 , more weight is given to the most recent average (Del Castillo, 2002).

The concept of JIT is based on philosophy that the inventory is waste. This means that the company must plan its needs for supplies to keep them on a minimum level which enables uninterrupted continuous running of the business process. In order to have required minimum supplies, the company must have reliable partners who deliver the supplies just in time when it is needed to use in the process. For this reason it is necessary to monitor the delivery time.

Delivery time is assumed to be only the time needed for a transport vehicle with supplies to come from point $\mathrm{A}$ to point $\mathrm{B}$, 
whereby A is a partner's warehouse and B is the warehouse of the company. Also it is assumed that there is no waiting time to start the delivery, which means that the partner is ready to send the supplies within just a few moments after the company ordered it.

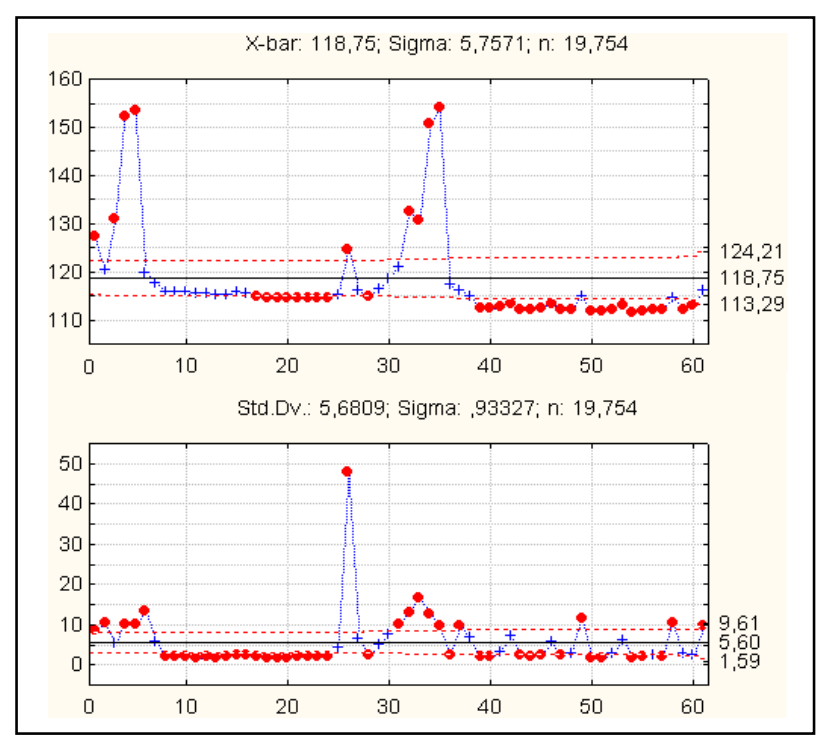

Fig. 1. $\bar{x}$ and s control chart

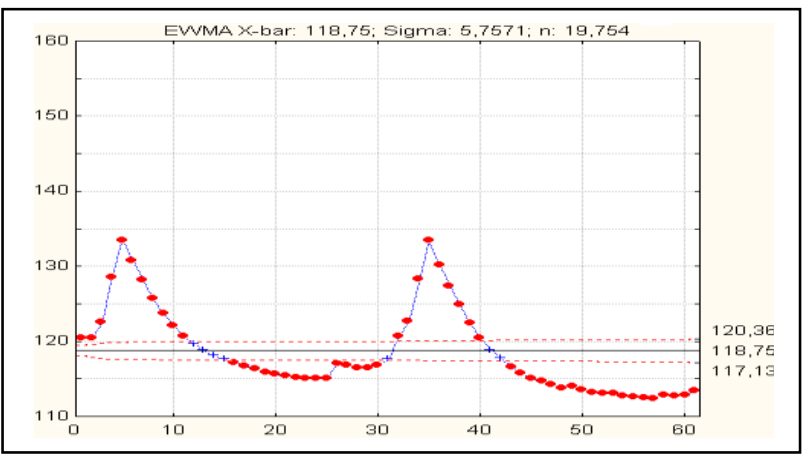

Fig. 2. EWMA control chart, $\lambda=0.2$

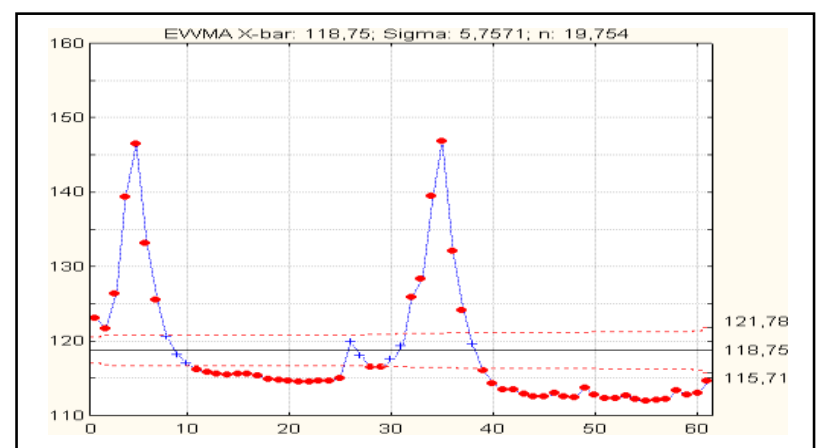

Fig. 3. EWMA control chart, $\lambda=0.5$

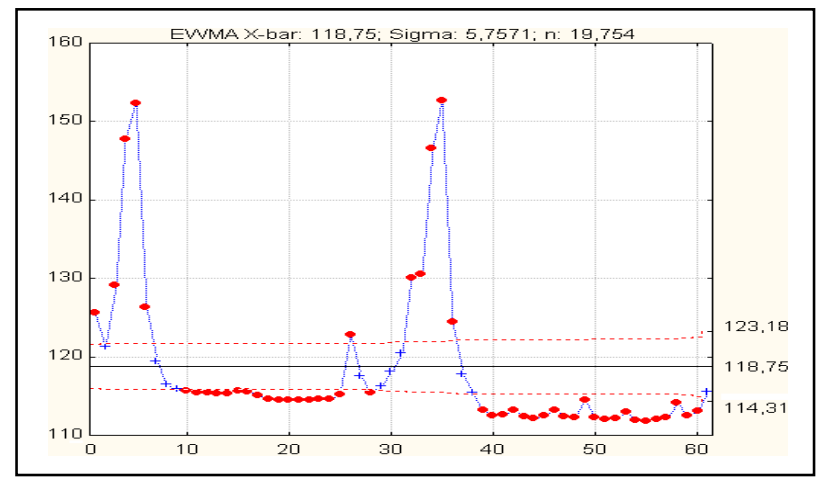

Fig. 4. EWMA control chart, $\lambda=0.8$
The most important thing here is how to estimate the right delivery time, because if the supplies came earlier than expected, then the company would have additional warehouse costs, and if the supplies came later than expected, then the company's production process would be stopped. The best way to make estimate is to observe some delivery times and then make conclusions about the average delivery time. Of course, it is important to observe deviations of the average time, too. The control charts cover both aspects of the analysis.

Because delivery time data are classified as business secrets, in this study, similar data are used. Namely, data for the lap times that the drivers of Formula 1 achieved on Grand Prix of Singapore in 2010 are used. Data about delivery times or lap times are taken from the F1 Fanatic, and are given in seconds. It is known that the most appropriate time for making deliveries is during night time, because the traffic intensity at that time is the lowest. The Grand Prix of Singapore is chosen because it is held in night conditions. The drivers of transport vehicles drive supplies to the company. 24 drivers started the race, so the $1^{\text {st }}$ delivery was made by 24 transport vehicles. The race consists of 61 laps, so, in total, 61 deliveries were made. The last (the $61^{\text {st }}$ ) delivery was made by only 10 drivers. For the purpose of calculating and drawing control charts, software Statistica 9 was used (see Fig. 1, 2, 3 and 4).

\section{CONCLUSION}

Since the time is a scarce resource, companies have to minimize its waste in order to achieve better business results. In this study the control of supply delivery time is applied using control charts for variables. The study has shown that the EWMA control chart is somewhat worthless in monitoring delivery time when the weight $\lambda$ is set at the very low level. On the other side, the $\bar{x}$ and the s control chart better indicate the deliveries in which some serious problems exist. However, the best outcome appears when all mentioned control charts are commonly applied.

In further analysis it is suggested to eliminate the problematic deliveries, and then come to the appropriate average delivery time. Of course, when planning deliveries, possible deviations from the calculated average time have to be kept in mind. The research treats a secondary data set only, and not the primary one, and this limitation should be overcome in the future research.

\section{REFERENCES}

Bersbach, P. (2009). The Seven Types of Waste a Summary, Available from:http://www.sixsigmatrainingconsulting.com /six-sigma-tools/the-seven-types-of-waste-a-summary/, Accessed: 2011-03-21

Booth, J. (1988). Beavers - changing to low inventory manufacturing. International Journal of Production Research, Vol. 26, No. 3, pp. 397-413, ISSN: 0020-7543

Del Castillo, E. (2002) Statistical Process Adjustment for Quality Control. John Wiley \& Sons, ISBN 0-471-43574-0, New York

F1 Fanatic (2010) 2010 Singapore Grand Prix - Lap Times, Available from: http://www.f1fanatic.co.uk/ /charts/201015rl.html, Accessed: 2011-03-25

Khoo, M.B.C. \& Quah, S.H. (2002). Proposed Short Runs Multivariate Control Charts for the Process Mean. Quality Engineering, Vol. 14, No. 4, pp. 603-621, ISSN: 0898-2112

Shewhart, W. A. (1925). The Application of Statistics as an Aid in Maintaining Quality of a Manufactured Product. Journal of the American Statistical Association, Vol. 20, No. 152, pp. 546-548, ISSN: 0162-1459

Takahashi, K. (2003). Comparing reactive Kanban systems. International Journal of Production Research, Vol. 41, No. 18, December 2003, pp. 4317-4337, ISSN: 0020-7543

Wadsworth, H.M.; Stephens, K.S. \& Godfrey, A.B. (2002) Modern Methods for Quality Control and Improvement, John Wiley \& Sons, ISBN 0-471-29973-1, New York 